Article

\title{
Comparison of the Fatty Acid and Triglyceride Profiles of Big Eye Tuna (Thunnus obesus), Atlantic salmon (Salmo salar) and Bighead Carp (Aristichthysnobilis) Heads
}

\author{
Jing Zhang ${ }^{1}$, Ningping Tao ${ }^{1, *}$, Yueliang Zhao ${ }^{1}$, Xichang Wang ${ }^{1}$ and Mingfu Wang ${ }^{1,2, *}$ \\ 1 College of Food Science and Technology, Shanghai Ocean University, Shanghai 201306, China; \\ D170202038@st.shou.edu.cn (J.Z.); ylzhao@shou.edu.cn (Y.Z.); xcwang@shou.edu.cn (X.W.) \\ 2 Food and Nutritional Science Program, School of Biological Sciences, The University of Hong Kong, \\ Hong Kong 999077, China \\ * Correspondence: nptao@shou.edu.cn (N.T.); mfwang@hku.hk (M.W.)
}

Received: 14 October 2019; Accepted: 2 November 2019; Published: 4 November 2019 updates

\begin{abstract}
Big eye tuna (Thunnus obesus), Atlantic salmon (Salmo salar) and bighead carp (Aristichthys nobilis) are three representative marine and fresh water fishes. In this study, the content of total lipids (TL), triglyceride (TG) fraction, and the fatty acid profiles in the corresponding fish heads were analyzed. Meanwhile, their complicated TG molecular species were further characterized. The results showed that TG was the major lipid in these three fish heads (60.58-86.69\%). Compared with other two fish heads, big eye tuna head was the most abundant in polyunsaturated fatty acids, among which eicosapentaenoic acid (EPA) + docosahexaenoic acid (DHA) accounted for $64.29 \%$ and $32.77 \%$ in the TL and TG fraction, respectively. It is also worth noting that EPA+DHA/total fatty acid (TFA) value of TL and TG fraction from bighead carp head showed no significant difference with Atlantic salmon head, a typical marine fish. There were $146 \mathrm{TG}$ molecules detected in big eye tuna head, 90 in Atlantic salmon and 87 in bighead carp heads. DHA or EPA accounted for $56.12 \%, 22.88 \%$, and $5.46 \%$ of the total TG molecules in these three fish heads, respectively. According to principal component analysis, orthogonal projection to latent structures-discriminant analysis and the constructed heat map, the three samples could be completely differentiated based on their TG molecule fingerprints. This study is the first to compare marine and fresh water fish from the perspective of their heads' fatty acid and TG molecule profiles.
\end{abstract}

Keywords: marine fish; fresh water fish; DHA; triglyceride molecular species

\section{Introduction}

Omega-3 ( $\omega-3)$ polyunsaturated fatty acids (PUFAs) are essential fatty acids which cannot be synthesized de novo by humans. Fish, flaxseed and some types of nuts such as walnuts are considered good sources of $\omega-3$ PUFA [1]. Among PUFA, docosahexaenoic acid (DHA) and eicosapentaenoic acid (EPA) are known as effective antioxidative substances. It is also reported that sufficient intake of $\omega-3$ PUFA shows neuroprotective activity and reduces the risk of cardiovascular diseases [2,3]. In addition, $\omega-3$ fatty acids are reported to have the ability to change the structure and function of lipid microdomains (lipid rafts and caveolae) and play a distinct role in the promotion of health effects through modulation of membrane-signaling proteins (which are located in raft regions) [4].

As one type of representative marine fish, tuna contains a high amount of $\omega-3$ PUFAs, typically EPA and DHA [5]. Salmon is also a good source of $\omega-3$ PUFAs, and Larsen et al. found that PUFA of New Zealand King salmon fillets contained about 46.26\% (EPA + DHA) [6]. Bighead carp (Aristichthys 
nobilis) is one of the four major fresh water fishes in China. Han and others [7] compared the fatty acid profiles of 15 major common fresh water fish muscles, the content of EPA + DHA in bighead carp was ranked as the fourth highest one. In addition, tuna, salmon and bighead carp are all widely consumed. The capture of big eye tuna (Thunnus boesus) was 472,934 tons in 2017, and the productions of Atlantic salmon (Salmo salar) and bighead carp in 2017 were 2,358,663 and 3,097,952 tons, respectively [8,9]. Their high content of EPA + DHA, and high production make these three fishes of great commercial potential.

High performance liquid chromatography (HPLC) with mass spectrum (MS) detection is an effective method to analysis triglyceride (TG) molecular species profiles. Non-aqueous reverse phase (NARP) mainly relies on carbon chain lengths and double bond numbers to separate TG molecules with different equivalent carbon number $(\mathrm{ECN})$, which is defined as the total carbon number in the acyl chains minus two times the number of double bonds in fatty acyl chains. In general, a molecule with a short fatty acid chain will elute before a long-chain molecule, and a molecule with a high degree of unsaturation will elute before a highly saturated molecule [10,11]. As most natural TG molecules contain fatty acids in the range of $C_{16}-C_{22}$, the utilization of a $C_{18}$ stationary phase will allow the maximum separation of TG molecules [12]. Electrospray ionization (ESI) is a soft ionization technique used for generating gas phase ions. In ESI analyses, a small amount of salt ions are often added to produce $\left[\mathrm{M}+\mathrm{NH}_{4}\right]^{+}$or $[\mathrm{Na}]^{+}$to perform the analysis [1,13-15]. Orbitrap and time of flight (TOF) mass spectrometers are two kinds of instruments of high resolution that are commonly used in metabolomics analysis. TOF instruments provide lipid profiling with high sensitivity, and Orbitrap instruments feature high resolution. Coupled with Orbitrap and TOF, Q Exactive provides the power of efficient data dependent acquisition, and acquires high resolution information of both precursors and fragments in the same analysis [16].

Fish heads are by-products generated during fish processing, which are normally used as fishmeal due to their low economic value Compared with other tissues fish heads might contain more abundant lipids aside from viscera. Meanwhile, the PUFA content is not low either $[17,18]$. Therefore, fish heads might a good source of lipids rich in PUFAs. In this study, the TG molecular species from big eye tuna, Atlantic salmon and bighead carp were determined and quantitatively analyzed using ultra high performance liquid chromatography (UHPLC)-Q E Orbitrap. Meanwhile, the corresponding lipid contents and fatty acid profile were also determined. This work will help to understand better of the lipid profiles from both marine and fresh water fishes, and provide a theoretical basis for the utilization of fish heads.

\section{Results and Discussion}

\subsection{Lipids Contents and Fatty Acid Profile of Fish Heads}

It was determined that the meat contents of big eye tuna, Atlantic salmon and bighead carp heads were $38.60 \pm 4.01,28.33 \pm 3.22$ and $43.05 \pm 6.67 \%$, respectively, while the total lipids contents in these three fish heads ranged from 5.61 to $15.67 \%$ of wet weight (Table 1), with the lipids contents in the two kinds of marine fish heads being markedly higher than that in big head carp heads.

Table 1. The lipids contents and determination of TG fraction in three kinds of fish heads. (\%, mean \pm S.D., $n=3$ ).

\begin{tabular}{cccc}
\hline Samples & Total Lipids & TG & Assay of TG Fraction \\
\hline Big eye tuna & $12.87 \pm 4.92^{\mathrm{b}}$ & $85.69 \pm 10.22^{\mathrm{a}}$ & $92.22 \pm 0.59^{\mathrm{b}}$ \\
Atlantic salmon & $15.67 \pm 2.01^{\mathrm{a}}$ & $60.58 \pm 8.32^{\mathrm{c}}$ & $98.52 \pm 0.39^{\mathrm{a}}$ \\
Bighead carp & $5.61 \pm 2.08^{\mathrm{c}}$ & $73.39 \pm 8.90^{\mathrm{b}}$ & $97.6 \pm 0.68^{\mathrm{a}}$ \\
\hline
\end{tabular}

${ }^{\mathrm{a}-\mathrm{c}}$ values in the same column with different lower-case letters are significantly different at $p<0.05$. 
The fatty acid profiles of the total lipids from the three kinds of fish heads were further analyzed (Table S1). Their major fatty acids were consistent with data reported in some previous studies [18-20]. As shown in Figure 1A, bighead carp heads showed a significantly higher $(p<0.05)$ level of monounsaturated fatty acids (MUFAs) $(61.81 \%)$ than Atlantic salmon $(46.78 \%)$ or big eye tuna (14.33) heads, respectively, while the two kinds of marine fish heads contained significantly higher $(p<0.05)$ amounts of PUFAs than bighead carp heads $(70.5 \%, 43.33 \%$ and $23.82 \%$, respectively). Compared with MUFA and PUFA, saturated fatty acids (SFAs) represented the smallest fraction in all three types of fish head $(15.16 \%, 9.37 \%$ and $14.37 \%)$.
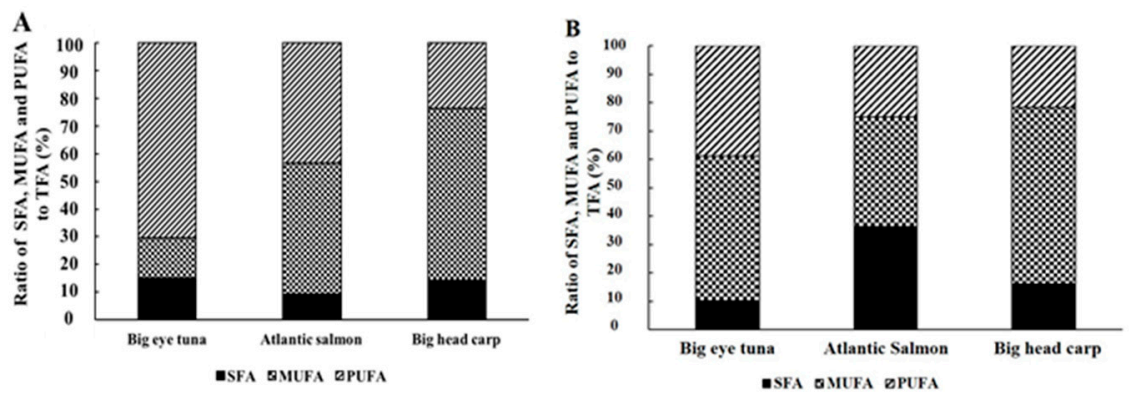

Figure 1. Ratio of SFA, MUFA, PUFA to TFA. (A) Total lipids, (B) TG fraction of the three kinds of fish heads.

Palmitic acid (16:0) was the major SFA in all three fish heads, accounting for $32.53 \%$, $57.33 \%$ and $31.84 \%$ of the SFAs in the three species. The consumption of palmitic is related to the risk of cardiovascular disease. Palmitoleic acid (16:1), which found in human skin and decreases with age, was the major MUFA in all three fish heads, with $29.85 \%, 52.19 \%$ and $67.87 \%$, respectively [21]. Large yellow croaker (Larimichthys crocea) is a typical marine fish species. Its muscle tissue contains $57.77 \%$ palmitic acid in the SFA fraction, and $22.88 \%$ palmitoleic acid in the MUFA fraction [22]. Meanwhile, tilapia is another major freshwater fish species. It was reported that 16:0 and 16:1 also are the predominant SFA and MUFA in tilapia heads, accounting for $68.8 \%$ and $13.78 \%$ of the SFA and MUFA, respectively [23].

EPA and DHA are two representative n-3 PUFAs that are widely found in marine triglycerides, phospholipids, ethyl esters and so on [24]. A large number of studies have demonstrated that dietary EPA and DHA could improve brain function, inhibit the activity of tumors and regulate lipid and glucose metabolism [25-28]. In this study, the amounts of EPA + DHA accounted for about 91.18, 34.42 and $53.18 \%$ in the PUFAs of the three kinds of fish heads. In contrast, the amount of EPA + DHA was $52.45 \%$ and $4.24 \%$ of PUFA in muscle of large yellow croaker and head of tilapia [22,23]. Meanwhile, the omega-3 indexes of big eye tuna, Atlantic salmon and bighead carp heads were 0.6 , 0.14 and 0.12 , respectively. It was reported that an omega- 3 index cut-point value $>0.08$ indicates a "low risk of coronary heart disease mortality" $[29,30]$. Therefore, it can be concluded that all three fish heads may serve as good potential sources of $\omega-3$ PUFA. TGs represented $85.69,60.58$ and $73.39 \%$ of the total lipids in these three kinds of fish heads, and the assays of separated TGs reached $92-99 \%$. As two representative marine fishes, the lipid contents in big eye tuna and Atlantic salmon heads were markedly higher than in bighead carp head $(p<0.05)$.

According to the distribution of SFA, MUFA and PUFA in the TG fraction (Figure 1B), the amount of UFA was higher than $60 \%$ in all three fish heads. Meanwhile, the TG fractions contained 32.77, 4.53 and $6.70 \%$ EPA + DHA, respectively. DHA was a major PUFA in the three fish heads, especially for big eye tuna, where it accounted for $81.78 \%$.

It is worth noting that the (EPA + DHA)/TFA value in both total lipids and TG fraction of big tuna head was significantly higher than in the other two types of fish heads. Notably, bighead carp was showed no significant difference with Atlantic salmon, which is a typical marine fish. In terms of TG fraction, the bighead carp level was even higher than in Atlantic salmon (Figure 2). Therefore, bighead carp, a kind of fresh water fish species, can be a good source of EPA and DHA. 


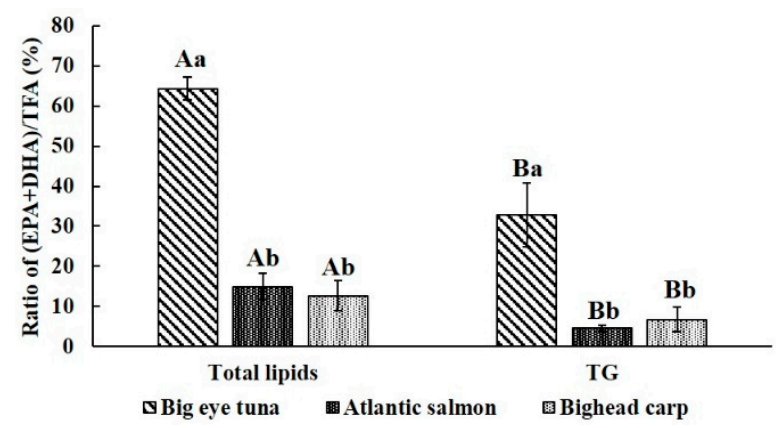

Figure 2. Ratio of (EPA + DHA) to TFA of total lipids and different classes of lipids. ${ }^{A, B}$ means a significant difference of total lipids and TG fraction, ${ }^{\mathrm{a}-\mathrm{c}}$ means a significant difference between the three different types of fish heads, $p<0.05$.

Besides that, the total lipids contained more EPA and DHA compared with the TG fraction in all three fish heads $(p<0.05)$. It could be speculated that the reason for this is that the total lipids is a mixture of different classes of lipids, including diglycerides, free fatty acids and phospholipids. Compared with the TG fraction, the other lipid components might contain more EPA and DHA.

\subsection{Characterization of TG Molecular Species in Different Kinds of Fish Heads}

Triglycerides (TG) are the major components in fish oil [31]. The WHO recommends that the consumption of 200-500 $\mathrm{mg}$ of fish oil is essential to satisfy the unsaturated fatty acid need in adults [24]. Besides that, EPA/DHA type of TG has higher bioavailability compared with the traditional ethyl ester (EE) EPA/DHA type [32]. The three fish heads were confirmed to be rich in PUFAs, especially EPA and DHA, in this study. If the fish heads could be used as a source of fish oil, it could represent a significant route for the high value utilization of byproducts. The physicochemical and nutritional properties of fish oil are determined mainly by the TG molecular species. Hence the TG molecule profile of the three fish heads was investigated. It is reported that EPA and DHA are not distributed randomly in a TG molecule, and the positional distribution of $\omega-3$ PUFAs, especially EPA and DHA, will strongly influence TGs' digestion and absorption [31].

Briefly, TGs are emulsified by intestinal peristalsis and bile salts, then hydrolyzed by enzymes in the intestinal lumen. The fatty acids at the sn- $1 / 3$ position are cleaved into free fatty acids. The hydrolyzed 2-monoglycerides and free fatty acids are absorbed by the intestinal epithelial cells and resynthesized into new triglyceride molecules, which are then transferred to the liver and adipose tissue via the lymphatic system and systemic circulation [33-36]. Hence, the identification of TG molecules may be helpful to reveal the beneficial effects of TG-fatty acids.

In this study, a UHPLC-Q E Orbitrap method was used to analyze the TG molecular species of big eye tuna, Atlantic salmon and bighead carp heads. High resolution mass spectrometry data-dependent analysis (HRMS-DDA) of positive ion modes were performed by Q E. The total ion chromatograms of the three kinds of fish heads in positive modes are shown in Figure 3. TG molecules could be selectively identified based on their loss of fatty acid chains. 


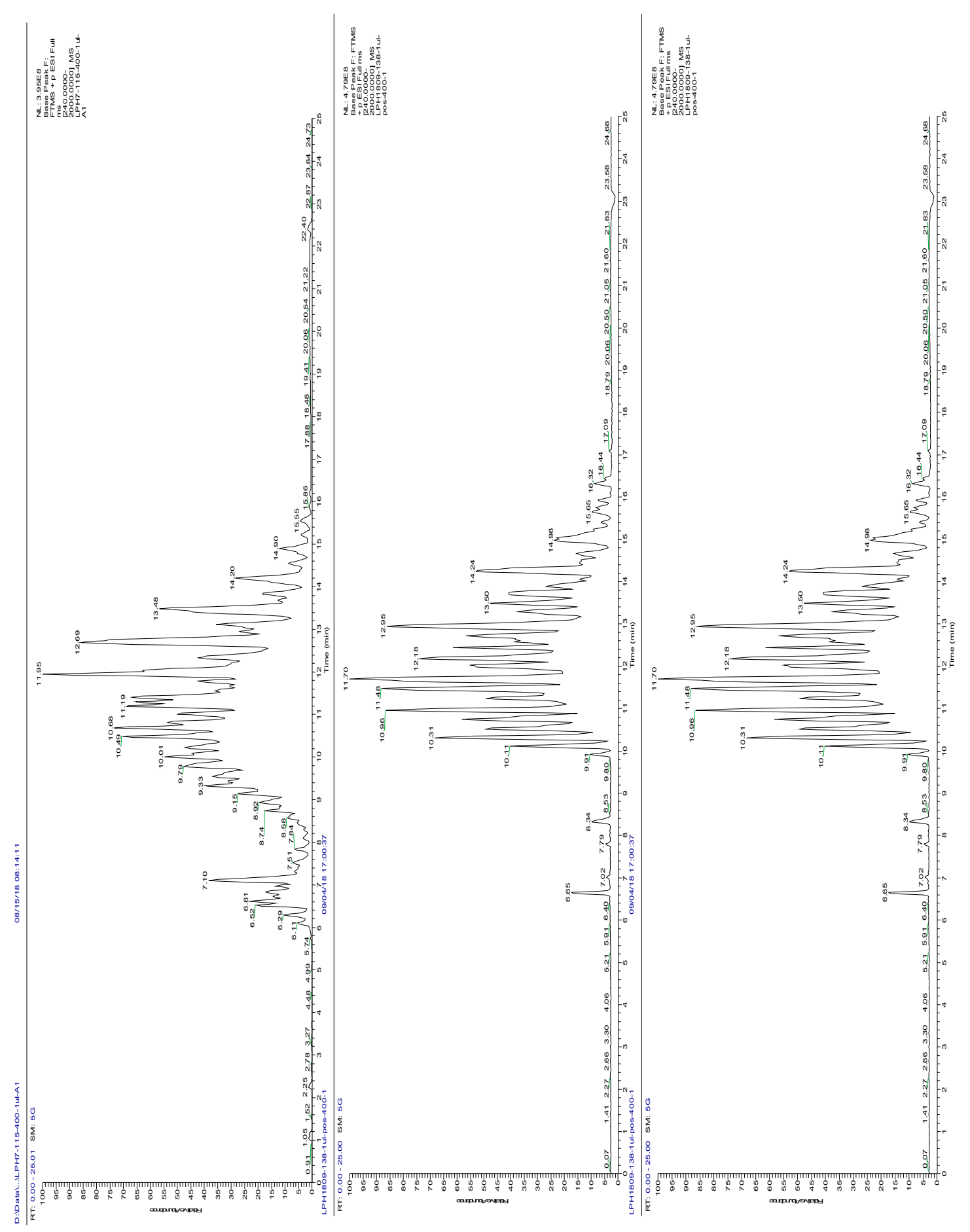

Figure 3. Total ion chromatogram of the three kinds of fish heads. Top, big eye tuna; middle, Atlantic salmon; bottom, bighead carp.

The basic comparison of TG content was not enough for the identification of different sources of lipids. For more specific characterization, the comparison of distribution of TG molecule species in the three samples was necessary. Previously, there was no report about the comparison of marine and fresh water fishes from the perspective of TG composition. Based on our LC-MS/MS analysis, a total of 208 TG molecule species, ranging from $m / z 766$ to 1035, were identified in big eye tuna, Atlantic salmon and bighead carp heads, respectively. Among them, 146 TG molecule species were found in big eye tuna head, 90 TG molecule species were detected in Atlantic salmon and 87 in bighead carp 
heads, respectively. There were a totally of 28 TGs detected in all three kinds of fish heads (Table 2). A full list of the detected TG molecules is provided along with their absolute quantification data in the Supplementary Material. Furthermore, the contents of different TG molecular species were quantitatively analyzed with internal and external standards. The calibration curves are shown in Figure S1.

Table 2. Common triglycerides of the lipids recovered from big eye tuna, Atlantic salmon and bighead carp heads ( $\mu \mathrm{g} / \mathrm{g}$ tissue).

\begin{tabular}{|c|c|c|c|c|}
\hline Measured $m / z$ & Molecular Species & Big Eye Tuna & Atlantic Salmon & Bighead Carp \\
\hline 796.73887 & TG (16:0/14:0/16:0) & $1.48 \pm 0.37^{a}$ & $0.07 \pm 0.03^{c}$ & $0.55 \pm 0.17^{b}$ \\
\hline 794.72322 & TG (16:0/14:0/16:1) & $1.52 \pm 0.33^{a}$ & $1.07 \pm 0.08^{\mathrm{a}}$ & $1.54 \pm 0.48^{\mathrm{a}}$ \\
\hline 808.73887 & TG (16:0/14:0/17:1) & $1.61 \pm 0.34^{\mathrm{a}}$ & $0.43 \pm 0.04^{b}$ & $1.35 \pm 0.41^{\mathrm{a}}$ \\
\hline 822.75452 & TG (16:0/14:0/18:1) & $6.09 \pm 1.34^{\mathrm{a}}$ & $2.07 \pm 0.16^{b}$ & $2.69 \pm 0.84^{b}$ \\
\hline 824.77017 & TG (16:0/16:0/16:0) & $1.68 \pm 0.42^{\mathrm{a}}$ & $0.14 \pm 0.02^{c}$ & $0.56 \pm 0.18^{b}$ \\
\hline 836.77017 & TG (16:0/16:0/17:1) & $0.17 \pm 0.11^{c}$ & $1.48 \pm 0.16^{b}$ & $2.39 \pm 0.77^{\mathrm{a}}$ \\
\hline 850.78582 & TG (16:0/16:0/18:1) & $10.54 \pm 2.64^{a}$ & $4.51 \pm 0.41^{b}$ & $3.33 \pm 1.04^{\mathrm{c}}$ \\
\hline 896.77017 & TG (16:0/16:0/22:6) & $14.6 \pm 3.42^{\mathrm{a}}$ & $2.36 \pm 0.16^{b}$ & $0.48 \pm 0.15^{\mathrm{c}}$ \\
\hline 862.78582 & TG (16:0/17:1/18:1) & $9.3 \pm 2.46^{\mathrm{a}}$ & $4.81 \pm 0.51^{b}$ & $2.94 \pm 0.94^{\mathrm{c}}$ \\
\hline 876.80147 & TG (16:0/18:1/18:1) & $1.23 \pm 0.39^{c}$ & $18.91 \pm 1.66^{\mathrm{a}}$ & $4.68 \pm 1.47^{b}$ \\
\hline 922.78582 & TG (16:0/18:1/22:6) & $20.25 \pm 19.13^{a}$ & $5.75 \pm 0.43^{b}$ & $1.38 \pm 0.61^{\mathrm{c}}$ \\
\hline 960.89537 & TG (16:0/18:1/24:1) & $1.88 \pm 1.19^{b}$ & $4.86 \pm 0.65^{\mathrm{a}}$ & $0.34 \pm 0.13^{c}$ \\
\hline 806.72322 & TG (16:1/14:0/17:1) & $0.61 \pm 0.21^{b}$ & $0.32 \pm 0.04^{b}$ & $1.04 \pm 0.32^{\mathrm{a}}$ \\
\hline 820.73887 & TG (16:1/14:0/18:1) & $0.49 \pm 0.13^{b}$ & $3.75 \pm 0.26^{\mathrm{a}}$ & $3.47 \pm 1.08^{\mathrm{a}}$ \\
\hline 818.72322 & TG (16:1/16:1/16:1) & $1.13 \pm 0.91^{\mathrm{c}}$ & $3.52 \pm 0.41^{\mathrm{a}}$ & $2.71 \pm 0.87^{b}$ \\
\hline 832.73887 & TG (16:1/16:1/17:1) & $2.4 \pm 2.78^{a}$ & $0.18 \pm 0.02^{\mathrm{c}}$ & $1.55 \pm 0.47^{b}$ \\
\hline 846.75452 & TG (16:1/16:1/18:1) & $1.74 \pm 1.33^{b}$ & $0.96 \pm 0.1^{\mathrm{c}}$ & $4.38 \pm 1.42^{\mathrm{a}}$ \\
\hline 874.78582 & TG (16:1/18:1/18:1) & $1.88 \pm 2.95^{c}$ & $25.83 \pm 2.31^{\mathrm{a}}$ & $4.35 \pm 1.41^{b}$ \\
\hline 904.83277 & TG (18:0/18:1/18:1) & $5.31 \pm 3.31^{b}$ & $15.89 \pm 1.5^{\mathrm{a}}$ & $2.31 \pm 0.77^{c}$ \\
\hline 888.80147 & TG (18:1/17:1/18:1) & $0.41 \pm 0.13^{c}$ & $5.62 \pm 0.63^{a}$ & $1.47 \pm 0.48^{b}$ \\
\hline 886.78582 & TG (18:1/17:1/18:2) & $4.98 \pm 1.47^{\mathrm{a}}$ & $3.76 \pm 0.37^{\mathrm{a}}$ & $1.33 \pm 0.43^{b}$ \\
\hline 944.86407 & TG (18:1/17:1/22:1) & $0.79 \pm 0.21^{b}$ & $1.31 \pm 0.18^{\mathrm{a}}$ & $0.23 \pm 0.08^{c}$ \\
\hline 934.78582 & TG (18:1/17:1/22:6) & $0.35 \pm 0.11^{\mathrm{a}}$ & $0.45 \pm 0.06^{\mathrm{a}}$ & $0.32 \pm 0.15^{a}$ \\
\hline 902.81712 & TG (18:1/18:1/18:1) & $4.26 \pm 3.85^{b}$ & $34.54 \pm 3.07^{\mathrm{a}}$ & $2.42 \pm 0.76^{b}$ \\
\hline 928.83277 & TG (18:1/18:1/20:2) & $0.61 \pm 0.33^{b}$ & $7.12 \pm 0.71^{\mathrm{a}}$ & $0.88 \pm 0.28^{b}$ \\
\hline 950.81712 & TG (18:1/18:1/22:5) & $3.64 \pm 1.88^{b}$ & $13.17 \pm 1.56^{\mathrm{a}}$ & $0.52 \pm 0.18^{c}$ \\
\hline 948.80147 & TG (18:1/18:1/22:6) & $8.92 \pm 7.94^{\mathrm{a}}$ & $6.41 \pm 0.47^{\mathrm{a}}$ & $0.85 \pm 0.29^{b}$ \\
\hline 986.91102 & TG (18:1/18:1/24:1) & $1.16 \pm 0.96^{b}$ & $5.65 \pm 0.71^{\mathrm{a}}$ & $0.11 \pm 0.04^{\mathrm{c}}$ \\
\hline 946.78582 & TG (18:1/18:2/22:6) & $9.33 \pm 3.78^{a}$ & $5.14 \pm 0.65^{b}$ & $0.8 \pm 0.38^{c}$ \\
\hline
\end{tabular}

${ }^{\mathrm{a}-\mathrm{c}}$ values in the same line with different lower-case letters are significantly different at $p<0.05$.

The accurate structure of an unknown TGs could be characterized according to its MS and MS/MS information. For example, based on the measured precursor ion $m / z 946\left(\left[\mathrm{M}+\mathrm{NH}_{4}\right]^{+}\right)$of a unknown TG molecule, the product ions with $m / z$ 601, 649, 656 were presented in its MS/MS spectrum. Then the fragments were matched with database using LipidSearch software v4.1.16 and identified as [DG $\left.(18: 1 / 18: 2)+\mathrm{NH}_{4}\right]^{+},\left[\mathrm{DG}(18: 1 / 22: 6)+\mathrm{NH}_{4}\right]^{+}$and $\left[\mathrm{DG}(18: 2 / 22: 6)+\mathrm{NH}_{4}\right]^{+}$, respectively (Figure 4) Hence, this TG could be speculated as TG (18:1/18:2/22:6). PUFAs are tend to located at sn-1/3 positions of TGs from marine mammals, and sn-2 position of TGs from fish oil [28,29]. Therefore, it could be speculated that 22:6 was located at sn-2 position, 18:1 and 18:2 were located at sn-1/3 position of this TG, respectively. 


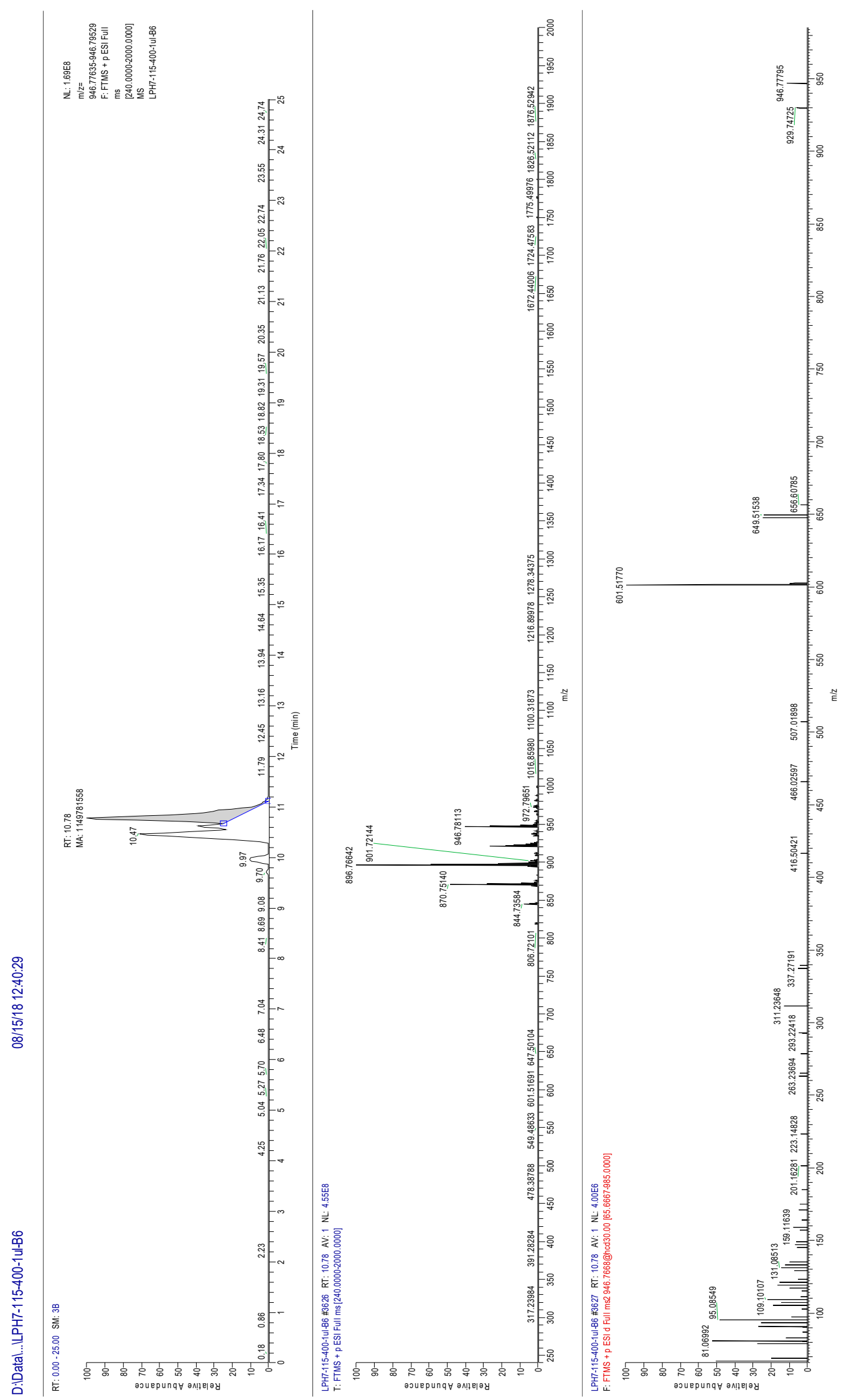

Figure 4. MS and MS/MS spectra of triglyceride (TG (18:1/18:2/22:6)). 
As listed in Table S3, TG (16:0/18:1/18:1) (14067.04 ng/ $\mu \mathrm{L}, 3.14 \%)$, TG (16:0/18:1/22:6) (24375.98 ng/ $\mu \mathrm{L}$,

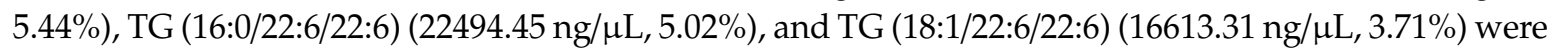
the dominant species in big eye tuna head. TG (18:1/18:1/18:1) $(31636.9 \mathrm{ng} / \mu \mathrm{L}, 6.48 \%), \mathrm{TG}(18: 1 / 18: 1 / 18: 2)$

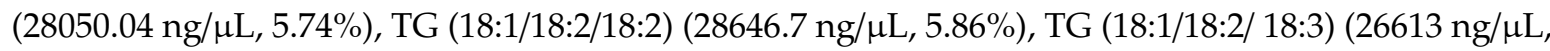
$5.45 \%)$, TG (18:3/18:2/18:2) (17218.12 ng/ $\mu \mathrm{L}, 3.53 \%)$, and TG (20:1/18:1/18:1) (14686.86 ng/ $\mathrm{LL}, 3.01 \%)$ were the dominant species in Atlantic salmon head. In bighead carp head, the dominant molecule species were TG (14:0/18:2/18:2) (10511.24 ng/ $\mu \mathrm{L}, 4.2 \%)$, TG (16:0/16:0/18:2) (10752.92 ng/ $\mu \mathrm{L}, 4.32 \%)$, TG (16:0/18:1/18:1) (9892.49 $\mathrm{ng} / \mu \mathrm{L}, 3.96 \%)$ and TG (16:1/16:1/18:1) (9257.75 ng/ $\mu \mathrm{L}, 3.70 \%)$.

Among the detected TG molecular species, there were 72 TG molecular species containing EPA or DHA in big eye tuna heads, accounting for $56.12 \%$ of the total TG molecules. Meanwhile, there were seven TG molecular species containing EPA or DHA in Atlantic salmon and bighead carp heads, accounting for 22.88 and $5.46 \%$ of total TG molecules (Figure 5). In terms of that, the three samples were significantly different with each other. The reason for this difference might be that big eye tuna and Atlantic salmon mainly feed on marine organisms rich in EPA and DHA, such as alewives, sea crab and shrimp, while bighead carp mainly feed on fresh water plankton, such as rotifers and cyanobacteria [37-39].

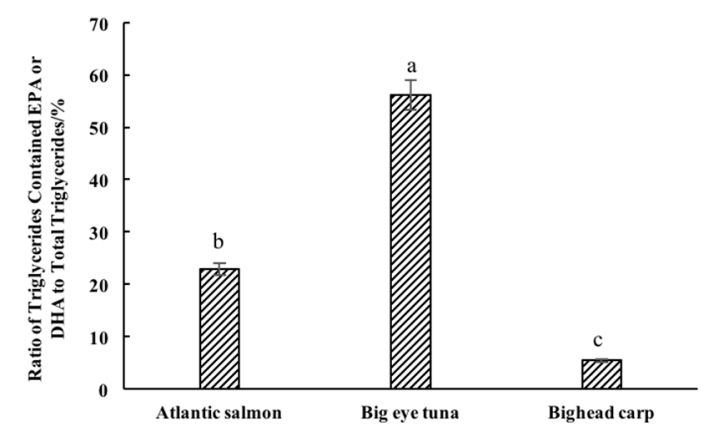

Figure 5. Ratio of triglyceride (TG) molecules contained EPA or DHA to total TG molecules. ${ }^{\mathrm{a}-\mathrm{c}}$ means significant difference, $p<0.05$.

In the past, Zhang and others [20] examined the positional distribution of fatty acids of TG molecules using pancreatic lipase, and calculated the TG composition using a Visual Basic program. Their results showed that there were 30-40 TG molecular species in marine fish oil extracted from tuna and salmon. The dominant TGs in tuna oil were TG (20:5/16:0/18:0), TG (20:5/14:0/14:0), TG (16:0/22:6/22:6) and TG (16:0/18:1/22:6), which accounted for nearly $30 \%$ of the total TGs. Meanwhile, TG (16:0/16:0/18:0), TG (22:6/18:1/18:0) and TG (18:1/18:1/18:0) were the major molecular species in salmon oil, where they accounted for more than $42 \%$ in the total TG molecules. In our study, TG (16:0/22:6/22:6) and TG (16:0/18:1/22:6) were also found as the dominant species in big eye tuna head, while TG (18:1/18:1/18:0) was the main TG molecular species found in Atlantic salmon head.

As shown in Figure 6(a1), the TG molecules of the three kinds of fish heads were clearly differentiated from each other. The aggregate quality control $(\mathrm{QC})$ value indicated that this UHPLC-Q E MS/MS method was able to distinguish the three samples based on their TG composition. The cumulative proportion for PC1 (which explained $74.8 \%$ of the variation) and PC2 (18\%) was $92.8 \%$. In order to improve the class separation and emphasize TG molecules responsible for sample separation, OPLS-DA was used by removing the structure noise affecting data matrix. As shown in Figure 6(a2-a4), with the removal of structure noise, there was a very effective separation among different kinds of fish heads with good predictive capability $(\mathrm{R} 2 \mathrm{X}=99.3,90.4$ and $97.3 \%, \mathrm{R} 2 \mathrm{Y}=98.8,97.3$ and $98.7 \%$, $\mathrm{Q} 2=98.3,88.3$ and $98.1 \%)$. 

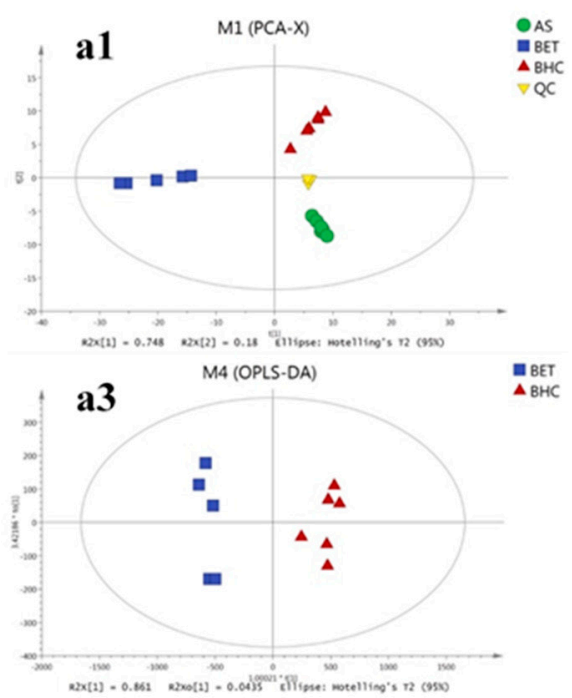

$\triangle \mathrm{BET}$
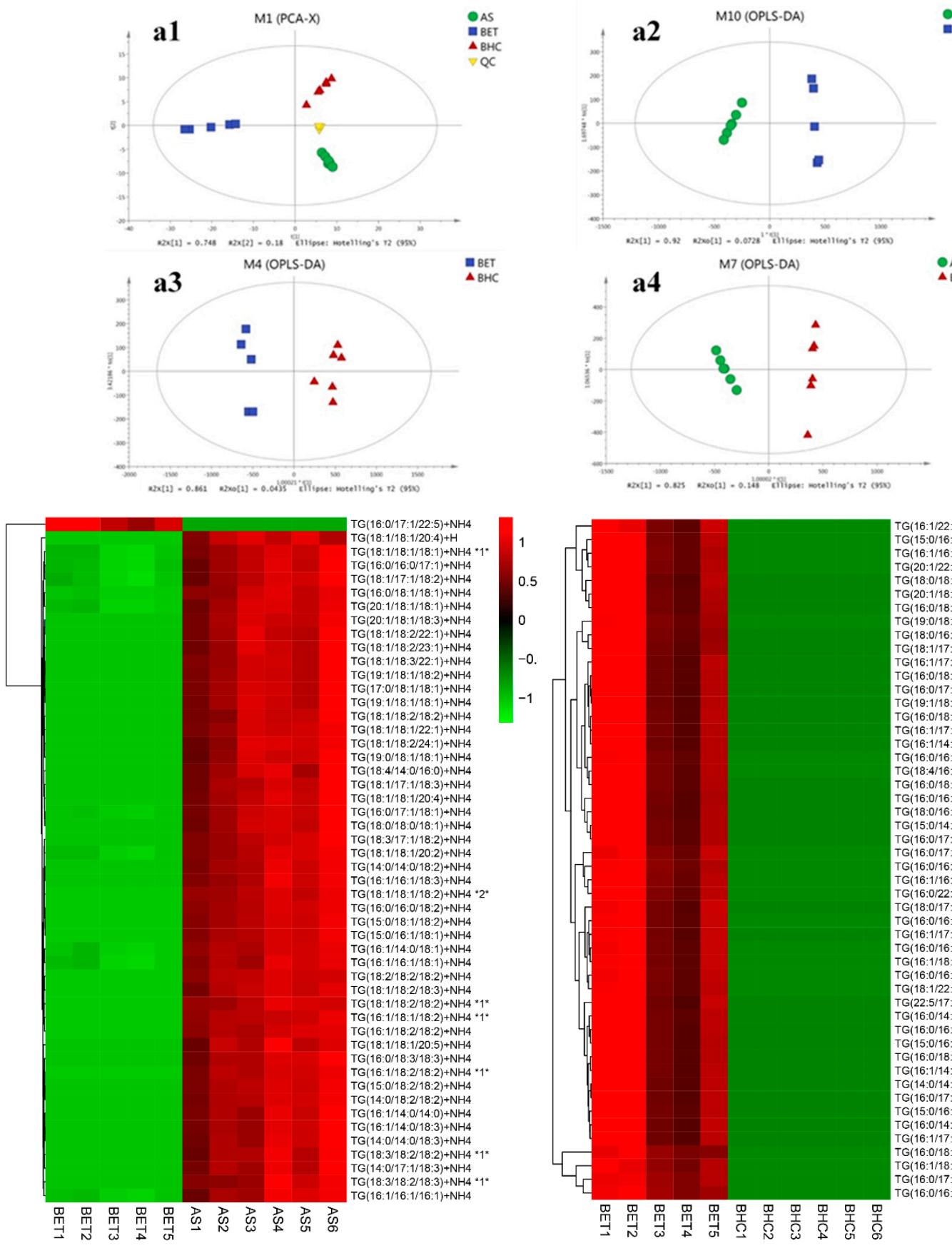

TG(16:0/17:1/22:5)+NH4 $T G(18: 1 / 18: 1 / 20: 4)+H$ TG(18:1/18:1/18:1)+NH4
TG(16:0/16:0/17:1)+NH4 $\mathrm{G}(16: 0 / 16: 0 / 17: 1)+\mathrm{NH} 4$ $\mathrm{G}(16: 0 / 18: 1 / 18: 1)+\mathrm{NH} 4$ $\mathrm{G}(20: 1 / 18: 1 / 18: 1)+N H 4$ TG(20:1/18:1/18:3)+NH4 G $\mathrm{G}(18: 1 / 18: 2: 22: 1 / 1)+\mathrm{NH} 4$ $\mathrm{TG}(18: 1 / 18: 3 / 22: 1)+\mathrm{NH} 4$ $\mathrm{G}(19: 1 / 18: 1 / 18: 2)+\mathrm{NH} 4$ $\mathrm{G}(17: 0 / 18: 1 / 18: 1)+\mathrm{NH} 4$ $\mathrm{TG}(19: 1 / 18: 1 / 1 / 18: 1)+\mathrm{NH} 4$ TG(18:1/18:2/18:2)+NH4
TG $(18: 1 / 18: 1 / 22: 1)+N H 4$ $\mathrm{G}(18: 1 / 18: 2 / 24: 1)+\mathrm{NH} 4$ $\mathrm{G}(19: 0 / 18: 1 / 18: 1)+\mathrm{NH} 4$ $\mathrm{G}(18: 4 / 14: 0 / 16: 0)+N H 4$ $\mathrm{G}(18: 1 / 17: 1 / 18: 3)+\mathrm{NH} 4$ G(18:1/18:1/20:4)+NH4 $\mathrm{G}(16: 0 / 17: 1 / 18: 1)+\mathrm{NH} 4$ TG(18:0/18:0/18:1)+NH4 (18:1/18:1/20:2)+NH4 $\mathrm{G}(14: 0 / 14: 0 / 18: 2)+\mathrm{NH} 4$ G $(16: 1 / 16: 1 / 18: 3)+N H 4$ (18:1/18:1/18:2)+NH4 G(16:0/16:0/18:2)+NH4 $(15: 0 / 16: 1 / 18: 1)+\mathrm{NH} 4$ G(16:1/16:1/18:1)+NH4 G(18:2/18:2/18:2)+NH4 (18.1/18.218.2)+NH4 * $\mathrm{G}(16: 1 / 18: 1 / 18: 2)+\mathrm{NH} 4{ }^{*}$ (16:1/18:2/18:2)+NH4 $G(18: 1 / 18: 1 / 120: 5)+N H 4$ G(16:0/18:3/18:3)+NH4 T(16.1/18.2/8.2)+NH4 (14:0118.218.2)+NH4 TG(16:1/14:0/14:0)+NH4 TG(16:1/14:0/18:3)+NH4 TG(14:0/14:0/18:3)+NH4 TG(18:3/18:2/18:2)+NH4 *1 TG(18:3/18:22118:3)+NH4 *1 $T G(16: 1 / 16: 1 / 16: 1)+N H 4$

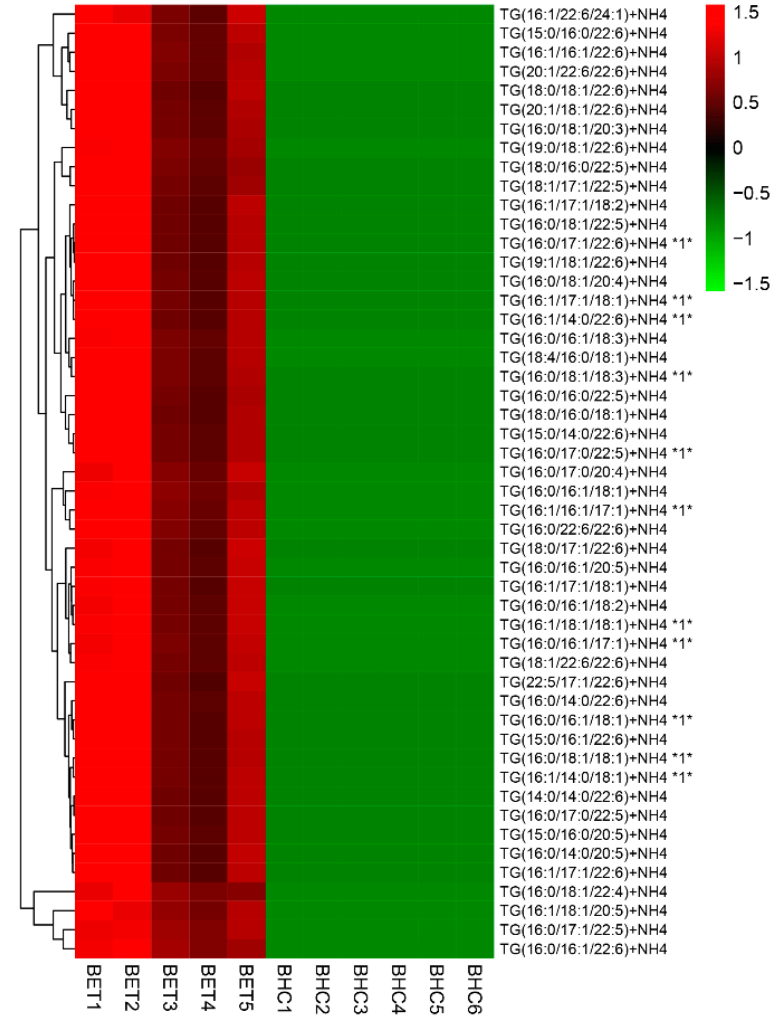

Figure 6. Cont. 


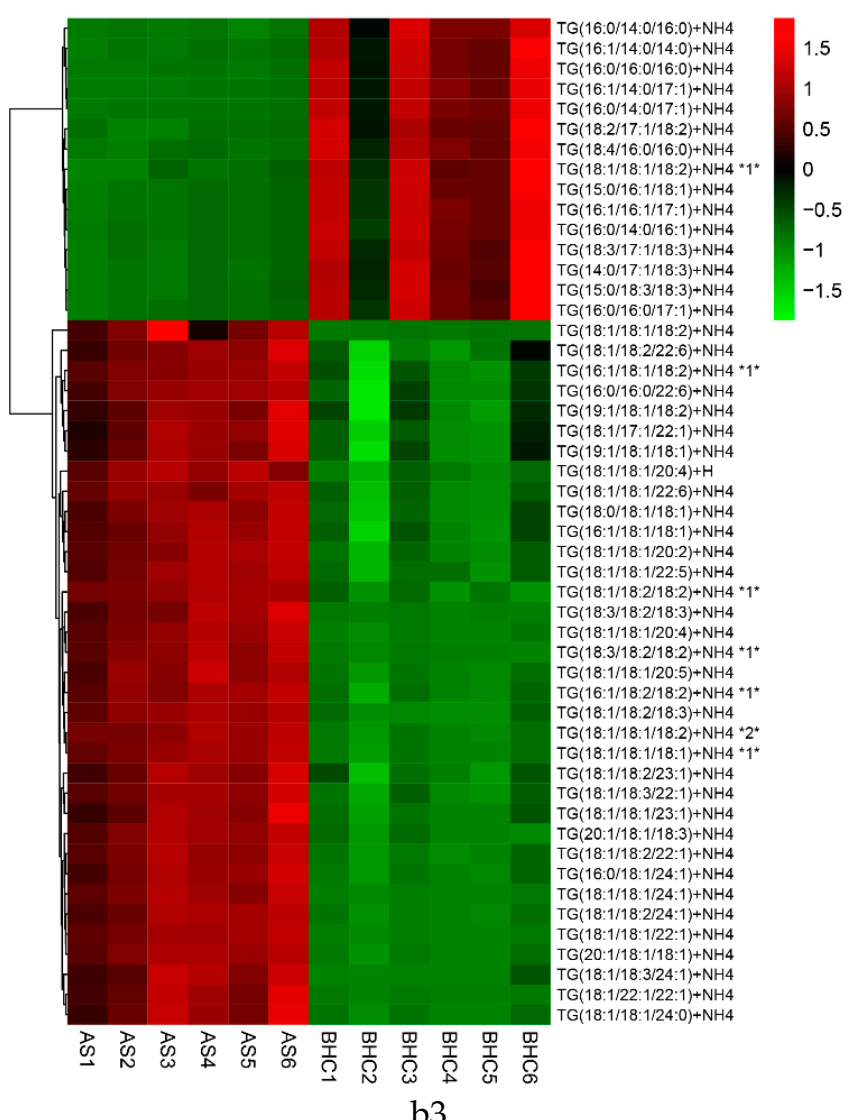

Figure 6. Multivariate statistical analysis and TOP-50 differential TG molecules of big eye tuna (BET), Atlantic salmon (AS) and bighead carp (BHC) heads. (a1) PCA (principal component analysis) of three kinds of fish heads; OPLS-DA (orthogonal projection to latent structures-discriminant analysis) of (a2) big eye tuna and Atlantic salmon; (a3) big eye tuna and bighead carp; (a4) Atlantic salmon and bighead carp; Top-50 differential TG molecules of (b1) big eye tuna and Atlantic salmon (b2) big eye tuna and bighead carp (b3) Atlantic salmon and bighead carp heads.

Variable importance in the projection (VIP) score was calculated using a weighted sum of the squared correlations between the OPLS-DA components and the original variables following the literature [40]. In this study, the TG profiles of three kinds of fish heads were compared in pairs, and TG molecules with VIP $>1$ and $p$ value $<0.05$ were selected as discriminants able to classify the three kinds of fish heads. Top-50 differential TG molecules of the three samples were shown in Figure 6(b1-b3). There were two, five and 23 TG molecules containing EPA or DHA in the top-50 differential metabolites in big eye tuna heads, Atlantic salmon and bighead carp heads, respectively. As for TG molecule composition, there are obvious distinctions existing between marine and fresh water fish, and different marine fish species.

\section{Materials and Methods}

\subsection{Materials}

Half big eye tuna heads (number: 30; length: $28.0 \pm 3.0 \mathrm{~cm}$; weight: $1.55 \pm 0.23 \mathrm{~kg}$ ), Atlantic salmon heads (number: 30 ; length: $15.88 \pm 1.20 \mathrm{~cm}$; weight: $0.60 \pm 0.1 \mathrm{~kg}$ ) and bighead carp heads (number: 30; length: $18.50 \pm 1.22 \mathrm{~cm}$; weight: $0.95 \pm 0.05 \mathrm{~kg}$ ) were purchased from Xiang Xiang Food Co., Ltd. (Dalian, Liaoning, P.R. China). Originally, the big eye tuna were captured in the Pacific-Indian Ocean region in September, the farmed Atlantic salmon was taken the Danish Faroe Islands in October, and the farmed bighead carp was obtained from Qiandao Lake in the Chinese Zhejiang region in October. 
The meat and bone of fish heads were divided using a scalpel, then the head meat was packaged at $30 \mathrm{~g} / \mathrm{bag}$ after homogenization at a rate of $5000 \mathrm{r} / \mathrm{min}$ for $10 \mathrm{~min}$ using a homogenizer (JHBE-30A, Fanzhi, Shanghai, China). Then the divided samples were stored at $-30{ }^{\circ} \mathrm{C}$ for a maximum of 4 weeks until use.

Organic solvents (including analytical and HPLC/gas chromatography (GC) grade), C19:0 and C19:0 FAME, and the mixture of 37 fatty acid methyl esters (FAME) were purchased from Shanghai ANPEL Scientific Instrument CO., Ltd. (Shanghai, P. R. China). According to the manufacturer, all the FAMEs in the mixture were of equal weight (i.e., $2.63 \%$ of the mixture). The TG standards used in this study were TG (18:1/18:1/18:0) and TG (16:0/18:0/16:0)-d5, all at $\geq 99 \%$ were purchased from Lordan (Solna, Sweden).

\subsection{Sample Preparation}

Total lipids were extracted according to the method of Folch and others [41]. Ten grams of head meat sample were mixed with $200 \mathrm{~mL}$ chloroform-methanol $(2: 1, v / v)$, and extracted for $24 \mathrm{~h}$ at $4{ }^{\circ} \mathrm{C}$. The extracted solution and residue were then divided by filtration. Then, $30 \mathrm{~mL}$ of $0.9 \% \mathrm{NaCl}$ solution was added into the extracted solution and kept at $4{ }^{\circ} \mathrm{C}$ for $8 \mathrm{~h}$, the lower chloroform phase was collected, the chloroform was removed by rotary vacuum evaporator (RV10, IKA, Staufen, Germany) at $40^{\circ} \mathrm{C}$. The extracted total lipids were stored at $-30^{\circ} \mathrm{C}$ for a maximum of 1 week until use.

The TG fraction of fish heads was purified using silica gel (100-200 mesh, Merck, Darmstadt, Germany) column chromatography [42]. Briefly, the silica gel column was equilibrated with dichloromethane $/ n$-hexane, 2:3 (v/v). Then the TG fraction was eluted using dichloromethane. The eluent was collected and the mobile phase was removed by rotary vacuum evaporator at $40{ }^{\circ} \mathrm{C}$. The remaining eluted lipids were weighed on an analytical balance (Mettler-Toledo, Zurich, Switzerland), respectively. Then the remaining eluted lipids were stored at $-30^{\circ} \mathrm{C}$ for a maximum of 1 week until use.

\subsection{TG Fraction Analysis}

The separated TG fraction was determined using an Iatroscan MK-6S thin layer chromatography-flame ionization detection (TLC-FID) Analyzer (Iatron Inc., Tokyo, Japan), according to the method of Yin [43].

\subsection{Determination of Fatty Acids Profiles}

The total lipids and TG fraction of big eye tuna, Atlantic salmon and bighead carp heads meats were converted to methyl ester derivatives following the method of Zhang [44]. Briefly, $0.1 \mathrm{~g}$ of lipids and $100 \mu \mathrm{L}$ of $\mathrm{C} 19: 0$ internal standard $(10 \mathrm{mg} / \mathrm{mL})$ were added into $5 \mathrm{~mL}$ of methanolic- $\mathrm{NaOH}$ $(0.5 \mathrm{~mol} / \mathrm{L})$. Then the mixture was in a condensing and concentrating equipment (HWS24, HongLang, Zhengzhou, Henan, P.R. China), heated at $100^{\circ} \mathrm{C}$ for $10 \mathrm{~min}$. After that, $3 \mathrm{~mL}$ boron trifluoride-methanol $\left(14 \%\right.$ in methanol) was added to the mixture at $100^{\circ} \mathrm{C}$ and stirred for $3 \mathrm{~min}$, followed by the addition of $2 \mathrm{~mL}$ n-hexane and holding at $100^{\circ} \mathrm{C}$ for $2 \mathrm{~min}$. Finally, $10 \mathrm{~mL}$ saturated $\mathrm{NaCl}$ solution was added to the mixture. The sample was cooled down to room temperature $\left(24-27^{\circ} \mathrm{C}\right)$, the upper n-hexane layer was collected using a $2 \mathrm{~mL}$ disposable syringe and purified with a nylon syringe filter $(13 \mathrm{~mm} \times$ $0.22 \mu \mathrm{m}$, ANPEL Inc., Shanghai, China) and stored in $2 \mathrm{~mL}$ thread screw neck vial with a septum $(32 \times$ $11.6 \mathrm{~mm}$, ANPEL Inc.) for further analysis.

GC analysis was carried out to determine the fatty acid profiles. A gas chromatograph TRACE GC ULTRA (Thermo Fisher Inc., Waltham, MA. USA) equipped with an Agilent (Santa Clara, CA. USA) SP-2560 capillary column (100 m length $\times 250 \mu \mathrm{m}$ internal diameter, $0.2 \mu \mathrm{m}$ of film) and a flame ionization detector (Thermo Fisher Inc.) was used. The temperature of the column ramp was: the initial temperature was $70^{\circ} \mathrm{C}$, heated to $140{ }^{\circ} \mathrm{C}\left(20^{\circ} \mathrm{C} / \mathrm{min}\right)$, held for $1 \mathrm{~min}$; then to $180^{\circ} \mathrm{C}\left(4{ }^{\circ} \mathrm{C} / \mathrm{min}\right)$, held for $1 \mathrm{~min}$; then to $225^{\circ} \mathrm{C}\left(3^{\circ} \mathrm{C} / \mathrm{min}\right)$, held for $30 \mathrm{~min}$. The gasifying temperature was $250^{\circ} \mathrm{C}$. The flow rate of $\mathrm{N} 2$ was $1 \mathrm{~mL} / \mathrm{min}$. The injection volume was $1 \mu \mathrm{L}$, with a split ratio of 45:1. FAME were identified by comparison of their retention time with standard mixture. The contents of different fatty 
acids were determined using the area ratio of GC peak of internal standard C19:0 and different fatty acids tested. The specific calculation formula as follows:

$$
\mathrm{X}_{\mathrm{i}}=\mathrm{F}_{\mathrm{i}} \times \frac{\mathrm{A}_{\mathrm{i}}}{\mathrm{A}_{\mathrm{C} 19: 0}} \times \frac{\mathrm{C}_{\mathrm{C} 19: 0} \times \mathrm{V}_{\mathrm{C} 19: 0} \times 1.047}{\mathrm{~m}} \times 100 \times \mathrm{F}_{\mathrm{FAMEi}-\mathrm{FAi}}
$$

where $\mathrm{Xi}$ is the contents of different fatty acids, $\mathrm{mg} / \mathrm{g}$; Fi is the response factor of each FAME; $\mathrm{Ai}$ is the peak area of each FAME in the sample; A19:0 is the peak area of the internal standard C19:0; CC19:0 is the concentration of $\mathrm{C} 19: 0, \mathrm{mg} / \mathrm{mL} ; \mathrm{VC} 19: 0$ is the volume of the internal standard $\mathrm{C} 19: 0, \mathrm{~mL} ; 1.047$ is the transfer coefficient of C19:0 to C19:0 FAME; FFAMEi-FAi is the transfer coefficient of FAME for each fatty acids; $\mathrm{m}$ is the mass of total lipids, in $\mathrm{g}$.

Fi was determined using the following expression:

$$
F_{i}=\frac{C_{S i} \times A_{19: 0}}{A_{S i} \times C_{19: 0}}
$$

where $\mathrm{C}_{\mathrm{Si}}$ is the concentration of each FAME in the mixed standard, $\mathrm{mg} / \mathrm{g} ; \mathrm{A}_{19: 0}$ is the peak area of $\mathrm{C}_{19: 0}$ FAME standard; $\mathrm{A}_{\mathrm{Si}}$ is the peak area of each FAME in the mixed standard; $\mathrm{C}_{19: 0}$ is the concentration of C19:0 FAME standard, mg/g. Fatty acid composition was expressed as mg/g of total lipids.

\subsection{Determination of TG Molecular Species}

An UHPLC method was used following the method published by Xu [16]. Briefly, an ultimate 3000 UHPLC (Dionex) coupled with a Q Exactive MS system (Thermo, Waltham, MA. USA) was used to perform LC separation. A Cortecs C18 column $(2.1 \times 100 \mathrm{~mm}$, Waters, Milford, MA, USA) was applied for analysis, the column chamber temperature was $40^{\circ} \mathrm{C}$. Mobile phase A was prepared by dissolving $0.77 \mathrm{~g}$ of ammonium acetate into $400 \mathrm{~mL}$ of HPLC-grade water, followed by adding $600 \mathrm{~mL}$ of HPLC-grade acetonitrile ( $\mathrm{pH} 7$ ). Mobile phase $\mathrm{B}$ was prepared by mixing $100 \mathrm{~mL}$ of acetonitrile with $900 \mathrm{~mL}$ isopropanol. The gradient was as followed: $0 \mathrm{~min}, 33 \% \mathrm{~B} ; 2.5 \mathrm{~min}, 33 \% \mathrm{~B} ; 5 \mathrm{~min}, 45 \% \mathrm{~B}$; $6 \mathrm{~min}, 52 \%$ B; $9 \mathrm{~min}, 58 \%$ B; $12 \mathrm{~min}, 66 \%$ B; $15 \mathrm{~min}, 70 \%$ B; $19.5 \mathrm{~min}, 98 \%$ B; $29.5 \mathrm{~min}, 98 \%$ B; $30 \mathrm{~min}$, $33 \% \mathrm{~B} ; 35 \mathrm{~min}, 33 \% \mathrm{~B}$. The flow rate was $0.25 \mathrm{~mL} / \mathrm{min}$.

The MS method followed the method published by $\mathrm{Xu}$ [16]. The detailed mass spectrometer parameters were as follows: spray voltage, $3.2 \mathrm{kV}$ for positive and $2.8 \mathrm{kV}$ for negative; capillary temperature, $320^{\circ} \mathrm{C}$; sheath gas flow rate (Arb), 35; aux gas flow rate (arb), 10; mass range $(\mathrm{m} / \mathrm{z})$, 240-2000 for positive and 200-2000 for negative; full MS resolution, 70,000; MS/MS resolution, 175,000; topN, 10; NCE, 15/30/45; duty cycle, $1.2 \mathrm{~s}$.

The obtained TG fraction of 2.3 was diluted 80 times (v:v) using dichloromethane/methanol (2:1, $v / v)$, the diluted TG was used to analyze. An absolute quantitative method using internal and external standards was carried out in this study. TG (16:0/18:0/16:0)-d5 was added to the samples as the internal standard at a concentration of $0.2 \mu \mathrm{g} / \mathrm{mL}$. TG (18:/18:1/18:0) was used as external standard. Like the samples to be tested, $0.2 \mu \mathrm{g} / \mathrm{mL}$ of TG (16:0/18:0/16:0)-d5 was added as an external standard. In the calibration curve, $\mathrm{Y}$ was peak area ratio of internal standard and external standard, and $\mathrm{X}$ was the content of TG (18:/18:1/18:0) precursor ion. The absolute content of tested TG molecules could be realized using put the ratio of internal standard and tested TG molecular precursor ion into the calibration equation. Injection volume of both samples and external standard was $1 \mu \mathrm{L}$.

\subsection{Data Analysis}

Lipids were identified using LipidSearch software v4.1.16 (Thermo). Adducts of $+\mathrm{NH} 4$ were applied for positive mode search as ammonium acetate was used in mobile phases. Results were expressed as mean \pm standard error of the mean. All statistical analyses were done using SPSS version 10.0 software (SPSS Institute, Inc., Chicago, IL, USA). $p$ values $<0.05$ were considered statistically significant. The raw MS data was exported into SIMCA-P (Umetrics, Malon, Sweden) to perform 
principal component analysis (PCA) and orthogonal projection to latent structures-discriminant analysis (OPLS-DA). Subsequently, heat maps were generated using R (http://www.r-project.org/).

\section{Conclusions}

Big eye tuna, Atlantic salmon and bighead carp are representative marine and fresh water fishes. TGs are major lipid class in all three kinds of fish heads. Compared with fresh water fish, marine fish heads, especially big eye tuna, contain higher contents of EPA and DHA. A total of 208 TG molecules were detected in these three kinds of fish heads, and the dominant TG molecules of each fish species head were identified. Based on unsupervised PCA and supervised OPLS-DA methods, the TG molecule compositions of the different fish species could be completely distinguished, and heat maps showed an obvious distinction between the marine and fresh water fish species.

Supplementary Materials: The following are available online at. Table S1: Fatty acids profiles of three kinds of fish heads; Table S2: Fatty acids profiles of different lipids classes in big eye tuna head; Table S3: Composition and contents of triglycerides in big eye tuna, Atlantic salmon and bighead carp heads; Figure S1: (A) Calibration curve of TG from big eye tuna head using TG (18:/18:1/18:0) as external standard and TG (16:0/18:0/16:0)-d5 as the internal standard, a total of 13 points were prepared to cover the peak area ratio of internal standard and external standard, injection volume is $1 \mu \mathrm{L}$. (B) Calibration curve of TG from Atlantic salmon and bighead carp heads using TG (18:/18:1/18:0) as external standard and TG (16:0/18:0/16:0)-d5 as the internal standard, a total of 13 points were prepared to cover the peak area ratio of internal standard and external standard, injection volume is $1 \mu \mathrm{L}$.

Author Contributions: Design of experiments, J.Z. and N.T.; methodology, J.Z. and N.T.; performance of experiments, J.Z.; analysis of data, J.Z., writing_original draft preparation, J.Z.; review and editing, N.T., M.W., X.W. and Y.Z.; supervision, N.T.

Funding: This research was funded by the National Key Research and Development Program of China, grant number 2016YFD0400202-8.

Conflicts of Interest: The authors declare no conflict of interest.

\section{References}

1. Herrera, L.C.; Ramaley, L.; Potvin, M.A.; Melanson, J.E. A method for determining regioisomer abundances of polyunsaturated triacylglycerols in omega-3 enriched fish oils using reversed-phase liquid chromatography and triple-stage mass spectrometry. Food Chem. 2013, 139, 655-662. [CrossRef] [PubMed]

2. Bays, H.E. Safety Considerations with Omega-3 Fatty Acid Therapy. Am. J. Cardiology 2007, 99, S35-S43. [CrossRef]

3. Bu, J.; Dou, Y.; Tian, X.; Wang, Z.; Chen, G.J.O.M. The Role of Omega-3 Polyunsaturated Fatty Acids in Stroke. Oxid. Med. Cell. Longev. 2016, 2016, 1-8. [CrossRef] [PubMed]

4. Siddiqui, R.A.; Harvey, K.A.; Zaloga, G.P.; Stillwell, W. Modulation of lipid rafts by Omega-3 fatty acids in inflammation and cancer: Implications for use of lipids during nutrition support. Nutr. Clin. Pract. 2007, 22, 74-88. [CrossRef] [PubMed]

5. Restuccia, D.; Spizzirri, U.G.; Bonesi, M.; Tundis, R.; Menichini, F.; Picci, N.; Loizzo, M.R. Evaluation of fatty acids and biogenic amines profiles in mullet and tuna roe during six months of storage at 4 degrees C. J. Food Compost. Anal. 2015, 40, 52-60. [CrossRef]

6. Larsen, D.; Quek, S.Y.; Eyres, L. Effect of cooking method on the fatty acid profile of New Zealand King Salmon (Oncorhynchus tshawytscha). Food Chem. 2010, 119, 785-790. [CrossRef]

7. Han, Y.L.; Lin, W.; Yang, S.; Li, L.; Huang, H.; Yang, X.; Wang, J.; Wu, Y.; Zhai, H.; Hao, S. Analysis of fat content and fatty acids composition in muscles of 15 species of freshwater fish. Sci. Tech. Food Ind. 2018, 20, 217-222.

8. FAO. Yearbook of fishery and aquaculture statistics 2017. Available online: http://www.fao.org/3/ca5495t/ ca5495t.pdf (accessed on 3 November 2019).

9. China Fishery Statistical Yearbook 2019; China Argriculture Press: Beijing, China, 2019; p. 25.

10. Sun, C.; Zou, X.Q.; Yao, Y.P.; Jin, J.; Xia, Y.; Huang, J.H.; Jin, Q.Z.; Wang, X.G. Evaluation of fatty acid composition in commercial infant formulas on the Chinese market: A comparative study based on fat source and stage. Int. Dairy J. 2016, 63, 42-51. [CrossRef] 
11. Sun, C.X.; Zhao, Y.Y.; Curtis, J.M. Elucidation of phosphatidylcholine isomers using two dimensional liquid chromatography coupled in-line with ozonolysis mass spectrometry. J. Chromatogr. A 2014, 1351, 37-45. [CrossRef]

12. $\check{R}$ Rezanka, T.; Pádrová, K.; Sigler, K.J.A.B. Regioisomeric and enantiomeric analysis of triacylglycerols. Anal. Biochem. 2016, 524, 3-12. [CrossRef]

13. Holcapek, M.; Dvorakova, H.; Lisa, M.; Giron, A.J.; Sandra, P.; Cvacka, J. Regioisomeric analysis of triacylglycerols using silver-ion liquid chromatography atmospheric pressure chemical ionization mass spectrometry: Comparison of five different mass analyzers. J. Chromatogr. A 2010, 1217, 8186-8194. [CrossRef] [PubMed]

14. Rezanka, T.; Sigler, K. Separation of Enantiomeric Triacylglycerols by Chiral-Phase HPLC. Lipids 2014, 49, 1251-1260. [CrossRef] [PubMed]

15. Momchilova, S.; Itabashi, Y.; Nikolova-Damyanova, B.; Kuksis, A. Regioselective separation of isomeric triacylglycerols by reversed-phase high-performance liquid chromatography: Stationary phase and mobile phase effects. J. Sep. Sci. 2006, 29, 2578-2583.

16. Xu, L.N.; Wang, X.Y.; Jiao, Y.P.; Liu, X.H. Assessment of potential false positives via orbitrap-based untargeted lipidomics from rat tissues. Talanta 2018, 178, 287-293. [CrossRef] [PubMed]

17. Guo, M.; He, C.; Zhang, S.; Wu, J.; Lin, G.; Li, C.; Cao, J. Fatty acids composition in different tissue of Trachinotus ovatus. Sci. Technol. Food Industry 2018, 39, 45-50.

18. Hong, H.; Fan, H.; Wang, H.; Lu, H.; Luo, Y.; Shen, H. Seasonal variations of fatty acid profile in different tissues of farmed bighead carp (Aristichthys nobilis). J. Food Sci. Technol. 2015, 52, 903-911. [CrossRef]

19. Chantachum, S.; Benjakul, S.; Sriwirat, N. Separation and quality of fish oil from precooked and non-precooked tuna heads. Food Chem. 2000, 69, 289-294. [CrossRef]

20. Zhang, H.J.; Shen, Y.B.; Zhang, Y.W.; Li, L.R.; Wang, X.G. Regiospecific Analysis of Fatty Acids and Calculation of Triglyceride Molecular Species in Marine Fish Oils. Biomed. Rese. Int. 2018, 2018, 1-7. [CrossRef]

21. Weimann, E.; Silva, M.B.B.; Murata, G.M.; Bortolon, J.R.; Dermargos, A.; Curi, R.; Hatanaka, E. Topical anti-inflammatory activity of palmitoleic acid improves wound healing. PLoS ONE 2018, 13. [CrossRef]

22. Gu, Z.X.; Mu, H.; Shen, H.H.; Deng, K.Y.; Liu, D.; Yang, M.X.; Zhang, Y.; Zhang, W.B.; Mai, K.S. High level of dietary soybean oil affects the glucose and lipid metabolism in large yellow croaker Larimichthys crocea through the insulin-mediated PI3K/AKT signaling pathway. Comp. Biochem. Physiol. B Biochem. Mol. Biol. 2019, 231, 34-41. [CrossRef]

23. Stevanato, F.B.; Cottica, S.M.; Petenuci, M.E.; Matsushita, M.; Desouza, N.E.; Visentainer, J.V. Evaluation of Processing, Preservation and Chemical and Fatty Acid Composition of Nile Tilapia Waste. J. Food Process. Preserv. 2010, 34, 373-383. [CrossRef]

24. Zhang, T.T.; Xu, J.; Wang, Y.M.; Xue, C.H. Health benefits of dietary marine DHA/EPA-enriched glycerophospholipids. Prog. Lipid Res. 2019, 75. [CrossRef] [PubMed]

25. Kerdiles, O.; Laye, S.; Calon, F. Omega-3 polyunsaturated fatty acids and brain health: Preclinical evidence for the prevention of neurodegenerative diseases. Trends Food Sci. Technol. 2017, 69, 203-213. [CrossRef]

26. Xu, X.P.; Li, Y.; Lu, X.L.; Sun, Y.Y.; Luo, J.M.; Zhang, Y.J. Glutaryl Polyamidoamine Dendrimer for Overcoming Cisplatin-Resistance of Breast Cancer Cells. J. Nanosci. Nanotechnol. 2018, 18, 6732-6739. [CrossRef]

27. You, J.H.; Zhuang, Y.F.; Cheng, J.; Lv, G.R.; Xie, J.X. Juvenile activity levels affect predisposition to metabolic syndrome induced by maternal hypoxia in male offspring rats. Int. J. Clin. Exp. Med. 2016, 9, 1422-1434.

28. Jin, J.Y.; Panserat, S.; Kamalam, B.S.; Aguirre, P.; Veron, V.; Medale, F. Insulin regulates lipid and glucose metabolism similarly in two lines of rainbow trout divergently selected for muscle fat content. Gen. Comp. Endocrinol. 2014, 204, 49-59. [CrossRef]

29. Harris, W.S.; Del Gobbo, L.; Tintle, N.L. The Omega-3 Index and relative risk for coronary heart disease mortality: Estimation from 10 cohort studies. Atherosclerosis 2017, 262, 51-54. [CrossRef]

30. Harris, W.S.; von Schacky, C. The Omega-3 Index: a new risk factor for death from coronary heart disease? Prev. Med. 2004, 39, 212-220. [CrossRef]

31. Wei, F.; Ji, S.X.; Hu, N.; Lv, X.; Dong, X.Y.; Feng, Y.Q.; Chen, H. Online profiling of triacylglycerols in plant oils by two-dimensional liquid chromatography using a single column coupled with atmospheric pressure chemical ionization mass spectrometry. J. Chromatogr. A 2013, 1312, 69-79. [CrossRef]

32. Ghasemifard, S.; Turchini, G.M.; Sinclair, A.J. Omega-3 long chain fatty acid "bioavailability": A review of evidence and methodological considerations. Prog. Lipid Res. 2014, 56, 92-108. [CrossRef] 
33. McClements, D.J. The biophysics of digestion: Lipids. Curr. Opin. Food Sci. 2018, 21, 1-6. [CrossRef]

34. Scorletti, E.; Byrne, C.D. Omega-3 fatty acids and non-alcoholic fatty liver disease: Evidence of efficacy and mechanism of action. Mol. Aspects Med. 2018, 64, 135-146. [CrossRef]

35. Serra, A.; Conte, G.; Ciucci, F.; Bulleri, E.; Corrales-Retana, L.; Cappucci, A.; Buccioni, A.; Mele, M. Dietary linseed supplementation affects the fatty acid composition of the sn-2 position of triglycerides in sheep milk. J. Dairy Sci. 2018, 101, 6742-6751. [CrossRef]

36. Zhang, R.J.; Zhang, Z.P.; Zou, L.Q.; Xiao, H.; Zhang, G.D.; Decker, E.A.; McClements, D.J. Enhancing Nutraceutical Bioavailability from Raw and Cooked Vegetables Using Excipient Emulsions: Influence of Lipid Type on Carotenoid Bioaccessibility from Carrots. J. Agric. Food. Chem. 2015, 63, 10508-10517. [CrossRef]

37. Bertrand, A.; Bard, F.X.; Josse, E. Tuna food habits related to the micronekton distribution in French Polynesia. Mar. Biol. 2002, 140, 1023-1037.

38. Brandt, S.B. Food of Trout and Salmon in Lake Ontario. J. Great Lakes Res. 1986, 12, 200-205. [CrossRef]

39. Ke, Z.-X.; Xie, P.; Guo, L.-G. Impacts of two biomanipulation fishes stocked in a large pen on the plankton abundance and water quality during a period of phytoplankton seasonal succession. Ecol. Eng. 2009, 35, 1610-1618. [CrossRef]

40. Rocchetti, G.; Lucini, L.; Gallo, A.; Masoero, F.; Trevisan, M.; Giuberti, G. Untargeted metabolomics reveals differences in chemical fingerprints between PDO and non-PDO Grana Padano cheeses. Food Res. Int. 2018, 113, 407-413. [CrossRef]

41. Folch, J.L.; Lees, M.; Stanley, S. A simple method for the isolation and purification of total lipids from animal tissues. J. Biol. Chem. 1957, 226, 497-509.

42. Saito, H.; Aono, H. Characteristics of lipid and fatty acid of marine gastropod Turbo cornutus: High levels of arachidonic and n-3 docosapentaenoic acid. Food Chem. 2014, 145, 135-144. [CrossRef]

43. Yin, F.W.; Zhou, D.Y.; Zhao, Q.; Liu, Z.Y.; Hu, X.P.; Liu, Y.F.; Song, L.; Zhou, X.; Qin, L.; Zhu, B.W.; et al. Identification of glycerophospholipid molecular species of mussel (Mytilus edulis) lipids by high-performance liquid chromatography-electrospray ionization-tandem mass spectrometry. Food Chem. 2016, 213, 344-351. [CrossRef]

44. Zhang, J.; Tao, N.P.; Wang, M.F.; Shi, W.Z.; Ye, B.Q.; Wang, X.C.; Zhu, Q.C.; Hua, C.X. Characterization of phospholipids from Pacific saury (Cololabis saira) viscera and their neuroprotective activity. Food Biosci. 2018, 24, 120-126. [CrossRef]

Sample Availability: Samples of the compounds are available from the corresponding authors.

(C) 2019 by the authors. Licensee MDPI, Basel, Switzerland. This article is an open access article distributed under the terms and conditions of the Creative Commons Attribution (CC BY) license (http://creativecommons.org/licenses/by/4.0/). 